\title{
Characteristics and outcomes of colorectal cancer surgery by age in a tertiary center in Korea: a retrospective review
}

\author{
Tae-Hoon Lee, Jeong Min Choo, Jeong Sub Kim, Seon Hui Shin, Ji-Seon Kim, Se-Jin Baek, \\ Jung-Myun Kwak, Jin Kim, Seon-Hahn Kim \\ Department of Surgery, Korea University College of Medicine, Seoul, Korea
}

Purpose: Colorectal cancer (CRC) occurs in all age groups, and the application of treatment may vary according to age. The study was designed to identify the characteristics of CRC by age.

Methods: A total of 4,326 patients undergoing primary resection for CRC from September 2006 to July 2019 were reviewed. Patient and tumor characteristics, operative and postoperative data, and oncologic outcome were compared Results: Patients aged 60 to 69 years comprised the largest age group (29.7\%), followed by those aged 50 to 59 and 70 to 79 (24.5\% and $23.9 \%$, respectively). Rectal cancer was common in all age groups, but right-sided colon cancer tended to be more frequent in older patients. In very elderly patients, there were significant numbers of emergency surgeries, and the frequencies of open surgery and permanent stoma were greater. In contrast, total abdominal colectomy or total proctocolectomy was performed frequently in patients in their teens and twenties. The elderly patients showed more advanced tumor stages and postoperative ileus. The incidence of adjuvant treatment was low in elderly patients, who also had shorter follow-up periods. Overall survival was reduced in older patients with stages 0 to 3 CRC $(\mathrm{P}<0.001)$, but diseasefree survival did not differ by age $(\mathrm{P}=0.391)$.

Conclusion: CRC screening at an earlier age than is currently undertaken may be necessary in Korea. In addition, improved surgical and oncological outcomes can be achieved through active treatment of the growing number of elderly CRC patients.

Keywords: Colorectal neoplasms; Hereditary cancer; Diagnosis; Chronology; Minimally invasive surgical procedures

\section{INTRODUCTION}

Colorectal cancer (CRC) is the third most common cancer in the world and the second most cancer in Korea [1,2]. Although the incidence rate has decreased slightly in recent years, the incidence and prevalence of CRC in Korea have increased with westerniza-

Received: Jul 20, 2021 - Revised: Aug 31, 2021 - Accepted: Sep 6, 2021

Correspondence to: Se-Jin Baek, M.D., Ph.D.

Department of Surgery, Korea University College of Medicine,

73 Goryeodae-ro, Seongbuk-gu, Seoul 02841, Korea

Tel: +82-2-920-6412, Fax: +82-2-928-1631

E-mail: xezin@korea.ac.kr

ORCID: https://orcid.org/0000-0002-3185-8777

(C) 2022 The Korean Society of Coloproctology

This is an open-access article distributed under the terms of the Creative Commons Attribution NonCommercial License (https://creativecommons.org/licenses/by-nc/4.0) which permits unrestricted non-

commercial use, distribution, and reproduction in any medium, provided the original work is properly cited. tion [3-6]. In the United States, a statistical analysis based on SEER (Surveillance, Epidemiology and End Results) data reported that the 5-year overall survival rate for CRC patients from 2006 to 2012 was $66.2 \%$, while $76.3 \%$ from 2010 to 2014 in Korea [2, 3]. This difference is believed to be the result of high level of medical treatment, active national cancer screening program, and national health insurance in Korea. However, the 5-year survival rates of CRC patients have been found to differ in different age groups [711]. According to Anele et al. [12], patients over the age of 60 years had lower survival rates compared to younger patients in even same stage. It is still unclear whether it was due to differences in tumor biology or because relatively passive treatments were selected for elderly patients.

Another issue related to the age of CRC patients is the use of screening programs. Currently, there are no guidelines that specifically address screening in the National Comprehensive Cancer 
Network (NCCN) or European Society for Medical Oncology guidelines. In Korea, the National Cancer Screening Program guidelines recommend a fecal occult blood test (FOBT) every year for those over 50 years of age. In case of abnormal results on FOBT, colonoscopy or double-contrast barium enema are recommended. Nonetheless, the FOBT is considered to have low accuracy and the initiation of screening at 50 years of age has been questioned.

In several studies, the characteristics of CRC patients in Eastern countries, especially in Korea, have been noted to differ from those in Western countries [3, 6, 13-15]. In particular, the neces- sity of starting screening earlier has been raised, as many cases of CRC occur at an earlier age than in the West [16-19]. In this study, we aimed to confirm the different characteristics in CRC by age group, thereby providing evidence to support future modifications of the therapeutic strategy and screening program in Korea.

\section{METHODS}

A total of 4,326 patients who underwent primary resection of CRC from September 2006 to July 2019 were included. Only patients with primary cancer and pathologically confirmed adeno-

Table 1. Patient characteristics of the study population

\begin{tabular}{|c|c|c|c|c|c|c|c|c|c|}
\hline \multirow{2}{*}{ Characteristic } & \multicolumn{9}{|c|}{ Age group (yr) } \\
\hline & $10-19$ & $20-29$ & $30-39$ & $40-49$ & $50-59$ & $60-69$ & $70-79$ & $80-89$ & $90-99$ \\
\hline No. of patients (\%) & $5(0.1)$ & $31(0.7)$ & $125(2.9)$ & 457 (10.6) & $1,060(24.5)$ & $1,287(29.7)$ & $1,035(23.9)$ & $309(7.1)$ & $17(0.4)$ \\
\hline Male sex (\%) & 40.0 & 58.1 & 56.0 & 56.2 & 65.7 & 63.6 & 59.3 & 48.2 & 47.1 \\
\hline Co-morbidity (\%) & 20.0 & 22.6 & 28.8 & 37.4 & 53.3 & 70.2 & 83.1 & 87.7 & 76.5 \\
\hline Endocrine & 0 & 6.5 & 4.0 & 9.6 & 14.2 & 24.8 & 28.7 & 26.5 & 17.6 \\
\hline Cardiovascular disease & 0 & 0 & 3.2 & 11.6 & 30.2 & 49.7 & 65.0 & 70.2 & 64.7 \\
\hline Pulmonary & 0 & 3.2 & 5.6 & 3.5 & 6.3 & 7.0 & 10.9 & 13.3 & 17.6 \\
\hline Etc. & 20.0 & 12.9 & 20.8 & 21.4 & 20.8 & 31.7 & 38.3 & 44.0 & 52.9 \\
\hline \multicolumn{10}{|l|}{ ASA PS classification (\%) } \\
\hline I & 80.0 & 45.2 & 46.4 & 40.3 & 30.0 & 18.5 & 7.4 & 6.1 & 11.8 \\
\hline$\|$ & 20.0 & 51.6 & 52.0 & 56.9 & 66.6 & 74.4 & 77.7 & 66.0 & 41.2 \\
\hline III & 0 & 3.2 & 0 & 2.0 & 2.5 & 6.4 & 13.3 & 23.3 & 47.1 \\
\hline IV & 0 & 0 & 0 & 0.2 & 0.1 & 0.2 & 0.5 & 2.3 & 0 \\
\hline V & 0 & 0 & 0 & 0 & 0.1 & 0 & 0 & 0 & 0 \\
\hline Unknown & 0 & 0 & 1.6 & 0.7 & 0.8 & 0.5 & 1.1 & 2.3 & 0 \\
\hline BMI $\left(\mathrm{kg} / \mathrm{m}^{2}\right)$, mean & 21.2 & 23.8 & 23.3 & 23.3 & 23.7 & 23.8 & 23.7 & 22.8 & 22.1 \\
\hline \multicolumn{10}{|l|}{ Tumor location (\%) } \\
\hline Right-sided colon & 20.0 & 22.6 & 19.2 & 15.8 & 20.6 & 24.3 & 29.8 & 29.8 & 41.2 \\
\hline Left-sided colon & 0 & 29.0 & 21.6 & 28.7 & 27.4 & 26.7 & 27.0 & 28.5 & 23.5 \\
\hline Rectum & 40.0 & 32.3 & 56.0 & 54.0 & 50.6 & 46.8 & 40.5 & 37.9 & 35.3 \\
\hline Multiple & 40.0 & 16.1 & 3.2 & 1.5 & 1.5 & 2.3 & 2.8 & 3.9 & 0 \\
\hline CEA (ng/mL), median & 1.2 & 1.7 & 2.0 & 2.5 & 2.1 & 2.4 & 2.3 & 3.0 & 5.0 \\
\hline CA19-9 (IU/mL), median & 15.5 & 11.1 & 11.5 & 12.5 & 11.3 & 12.3 & 13.2 & 15.0 & 15.8 \\
\hline Neoadjuvant treatment (\%) & 0 & 25.8 & 26.4 & 25.2 & 15.3 & 13.3 & 7.6 & 7.4 & 0 \\
\hline Chemotherapy & 0 & 3.2 & 4.8 & 6.8 & 4.3 & 3.4 & 1.9 & 1.3 & 0 \\
\hline Radiotherapy & 0 & 0 & 4.0 & 4.8 & 1.8 & 2.1 & 1.3 & 1.9 & 0 \\
\hline CCRT & 0 & 22.6 & 19.2 & 16.6 & 10.5 & 8.5 & 5.3 & 4.9 & 0 \\
\hline Preoperative complication (\%) & 20.0 & 16.1 & 14.4 & 17.1 & 12.7 & 10.2 & 13.4 & 22.0 & 23.5 \\
\hline Treatment (\%) & 0 & 6.5 & 4.0 & 7.7 & 5.8 & 4.0 & 6.0 & 11.3 & 11.8 \\
\hline
\end{tabular}

ASA, American Society of Anesthesiologists; PS, physical status; CEA, carcinoembryonic antigen; CA19-9, carbohydrate antigen 19-9; CCRT, concurrent chemoradiotherapy.

${ }^{a}$ Duplicated. 
carcinoma located from the appendix to the rectum were included in the study. Recurrent cancer, metastasis of other cancers, and patients who underwent diversion without resection were excluded. This study was approved by the Institutional Review Board of Korea University Anam Hospital (No. 2020AN0528) and all participants provided informed consent.

Tumors located in the appendix, cecum, ascending, hepatic flexure, and transverse colon were classified as right-sided colon cancer, while splenic flexure, descending, and sigmoid colon cancer were classified as left-sided colon cancer. Rectosigmoid colon cancers were classified as rectal cancer. Since 2006, our hospital has been performing most surgeries using a minimally invasive approach. In addition, D3 lymphadenectomy is routinely performed with curative intent for all CRC. Because the types of surgery were so diverse in this study, they were classified into lesional radical operations (including complete mesocolic excision [CME] or total mesorectal excision [TME], total surgery [total abdominal colectomy or total proctocolectomy], and limited surgery).

Perioperative evaluation and treatment were conducted based on the NCCN guidelines. All patients were evaluated preoperatively by physical examination, total colonoscopy, abdominopelvic computed tomography (CT), chest $\mathrm{CT}$, and routine laboratory tests, which included tumor markers. If necessary, additional tests, such as rectal magnetic resonance imaging (MRI), liver MRI, and positron emission tomography-CT were performed. Stent insertion, neoadjuvant chemotherapy, or radiotherapy were performed before surgery if needed. Routinely, the patients were allowed water the day after surgery and a soft diet on the second day after surgery. Adjuvant treatment after surgery was performed in consideration of cancer stage, age, general condition, and socioeconomic status. Follow-up examinations were carried out at 3 -month intervals during the first 2 years postoperatively, at 6-month intervals until 5 years after surgery, and then annually if there was no evidence of recurrence.

The 4,326 patients were divided by age in order to compare their clinical and tumor characteristics, operative and postoperative data, and oncologic outcomes. Descriptive results were presented as a mean or median for continuous outcomes, and as frequency and percentage for categorical outcomes. Student t-test or analysis of variance were used to compare continuous variables, and the chi-square test or Fisher exact test were applied for categorical variables. Five-year overall survival (OS) and disease-free survival (DFS) were estimated using the Kaplan-Meier method and differences in survival were analyzed with the log-rank test. All statisti$\mathrm{cal}$ analyses were performed using IBM SPSS Statistics ver. 22.0 (IBM Corp., Armonk, NY, USA). A P-value less than 0.05 was considered statistically significant.

\section{RESULTS}

CRC patients aged 60 to 69 years comprised the largest group, followed by those aged 50 to 59 years and 70 to 79 years $(10-19$ years, $0.1 \%$; $20-29$ years, $0.7 \%$; $30-39$ years, $2.9 \%$; $40-49$ years, $10.6 \%$; $50-59$ years, $24.5 \%$; $60-69$ years, $29.7 \%$; $70-79$ years, $23.9 \%$; $80-89$ years, $7.1 \%$; and $90-99$ years, $0.4 \%)$. Males comprised the highest ratio in the 50s and 60s, and the younger or older ages had a higher proportion of females. The presence of comorbidities, in particular cardiovascular disease, increased with patient age; however, it was present in a lower percentage of patients aged 90 to 99 years than in those aged 70 to 79 years or 80 to 89 years. The American Society of Anesthesiologists (ASA) physical status (PS) classification tended to increase with age, but the ratio of ASA PS grade I was relatively high among patients aged 90 to 99 years. The body mass index was low in very young and very elderly patients.

Although rectal cancer was most common in all age groups, the proportion of right-sided colon cancer tended to increase with age. Right-sided colon cancer was most frequently reported among patients aged 90 to 99 years. In young ages, $40 \%$ of patients represented multiple lesions. The preoperative tumor marker levels did not differ significantly between groups. Preoperative complication rate was high in very young and very elderly patients, and the rate of neoadjuvant treatment was also low in these groups (Table 1).

In patients aged 90 to 99 years, the rate of emergency surgery was significantly high. Most of the surgery was performed by laparoscopy in all age groups, and the proportion of robotic surgery was relatively high in young patients (20-29 years, 35.5\%; 30-39 years, $34.4 \%$; and $40-49$ years, $30.9 \%$ ), while the rate of open surgery was relatively high in the elderly $(80-89$ years, $7.4 \%$ and 90-99 years, $11.8 \%$ ) (Table 2, Fig. 1).

The majority of patients underwent radical operations, including CME or TME, while the rate of total abdominal colectomy or total proctocolectomy was high in young patients (10-19 years, $60.0 \%$ and $20-29$ years, $25.8 \%$ ). The proportion of patients who underwent combined operations did not differ between groups, but the rate of permanent stoma was high in elderly patients (90-99 years, 11.8\%). The operation time tended to be shorter as the patient's age increased.

In pathology evaluations, older patients had more advanced $\mathrm{T}$ and TNM stages, and larger tumor sizes (Table 3). However, the $\mathrm{N}$ stage, $\mathrm{M}$ stage, number of positive lymph nodes (LNs), proximal resection margin, and circumferential resection margin did not differ significantly between groups. In young patients, the number of retrieved LNs was significantly greater, and distal resection margin was longer. In elderly patients, gas passing, defecation, and soft diet intake were delayed after surgery. In contrast, the duration of hospital stay after surgery did not differ between groups. The overall complication rate was $26.4 \%$ and the leakage rate was $5.5 \%$. In older patients, the postoperative complication rate was high: ileus occurred in a greater percentage of patients aged 90 to 99 years (35.3\%). Reoperation did not differ between the groups, but postoperative mortality was significantly higher in elderly patients (Table 4). 
Table 2. Operative data for the study population

\begin{tabular}{|c|c|c|c|c|c|c|c|c|c|}
\hline \multirow{2}{*}{ Variable } & \multicolumn{9}{|c|}{ Age group (yr) } \\
\hline & $10-19$ & $20-29$ & $30-39$ & $40-49$ & $50-59$ & $60-69$ & $70-79$ & $80-89$ & $90-99$ \\
\hline Emergency (\%) & 0 & 6.5 & 4.8 & 2.4 & 1.8 & 1.6 & 2.1 & 4.9 & 17.6 \\
\hline \multicolumn{10}{|l|}{ Operation type (\%) } \\
\hline Laparoscopy & 80.0 & 58.1 & 53.6 & 58.4 & 69.3 & 75.0 & 80.8 & 74.4 & 76.5 \\
\hline Robotic & 20.0 & 35.5 & 34.4 & 30.9 & 21.6 & 17.3 & 11.1 & 10.4 & 11.8 \\
\hline Open & 0 & 3.2 & 6.4 & 6.1 & 4.0 & 4.8 & 4.3 & 7.4 & 11.8 \\
\hline Conversion & 0 & 3.2 & 1.6 & 1.5 & 2.0 & 1.0 & 1.7 & 3.6 & 0 \\
\hline Transanal & 0 & 0 & 4.0 & 3.1 & 3.1 & 1.9 & 2.1 & 4.2 & 0 \\
\hline \multicolumn{10}{|l|}{ Operation name (\%) } \\
\hline Lesional (CME, TME) & 40.0 & 74.2 & 90.4 & 94.3 & 95.2 & 94.8 & 94.6 & 92.2 & 100 \\
\hline Total (TAC, TPC) & 60.0 & 25.8 & 4.8 & 1.8 & 1.0 & 2.3 & 1.8 & 2.3 & 0 \\
\hline Multiple & 0 & 0 & 0 & 0.7 & 0.3 & 0.5 & 1.0 & 1.0 & 0 \\
\hline Limited (segmental, TAE, TAMIS) & 0 & 0 & 4.8 & 3.3 & 3.5 & 2.3 & 2.6 & 4.5 & 0 \\
\hline Combined operation (\%) & 0 & 9.7 & 15.2 & 15.5 & 10.6 & 10.8 & 11.9 & 8.1 & 11.8 \\
\hline Permanent colostomy (\%) & 0 & 3.2 & 0 & 4.8 & 3.0 & 2.3 & 3.6 & 5.8 & 11.8 \\
\hline Operative time (min), median & 200 & 213 & 200 & 205 & 190 & 190 & 175 & 165 & 140 \\
\hline $\mathrm{EBL}(\mathrm{mL})$, mean & 0 & 129.0 & 66.6 & 91.7 & 98.5 & 85.6 & 87.9 & 112.9 & 17.7 \\
\hline
\end{tabular}

CME, complete mesocolic excision; TME, total mesorectal excision; TAC, total abdominal colectomy; TPC, total proctocolectomy; TAE, transanal excision; TAMIS, transanal minimally invasive surgery; EBL, estimated blood loss.

In elderly patients, postoperative treatment, especially chemotherapy, was rarely performed, and the follow-up period was shorter (Table 4). When survival analysis was performed in those with stage 1 to 3 disease, 5-year OS was significantly different between age groups (10-19 years, not applicable [NA]; 20-29 years, 90.9\%; 30-39 years, $92.2 \%$; 40-49 years, $90.0 \%$; $50-59$ years, 92.4\%; 60-69 years, $87.9 \%$; 70-79 years, $82.8 \%$; $80-89$ years, 54.4\%; and 90-99 years, $0 \%$; $\mathrm{P}<0.001)$; however, there was no difference in 5-year DFS (10-19 years, NA; 20-29 years, NA; $30-39$ years, $98.6 \%$; 40-49 years, $95.5 \%$; 50-59 years, $96.2 \%$; 60-69 years, $97.2 \%$; 70-79 years, $97.6 \%$; $80-89$ years, $90.3 \%$; and 90-99 years, $\mathrm{NA} ; \mathrm{P}=0.391$ ) (Fig. 2).

\section{DISCUSSION}

In our study, we found various surgical techniques were performed for CRC in all ages, including elderly patients. Patients aged 50 to 79 years accounted for the majority of those who underwent surgery; however, even compared to the national cancer statistics in Korea, there was a greater proportion of young patients in our study population. According to Korean national cancer statistics, out of a total of 28,127 new CRC patients in 2016, 17 patients $(0.06 \%)$ were 10 to 19 years of age, $98(0.34 \%)$ were 20 to $29,609(2.16 \%)$ were 30 to $39,2,202(7.83 \%)$ were 40 to $49,5,969$ (21.2\%) were 50 to $59,7,453(26.5 \%)$ were 60 to $69,7,492(26.6 \%)$ were 70 to 79 , and 4,287 (15.2\%) were 80 to 89 . Compared to our data, the age distribution was shifted to the right. This difference is likely the result of including only patients who underwent surgery in our study.

In elderly patients, active treatments such as surgery may be selected less frequently. Although age is not an independent factor, surgical treatment for elderly patients is sometimes not recommended due to comorbidities and poor overall health [20-22]. In our study, the presence of comorbidities tended to be low among elderly patients. Perhaps this is because only patients in good general condition were selected for elective surgery. In our study, the 90s group had shorter operative times and less estimated blood loss (EBL) than patients of other age groups. The high rate of open surgery was thought to contribute to this. In addition, the absence of elective cases requiring massive dissection and the small sample size were also likely causes of low EBL deviation.

Even when considering that our study included only patients who underwent surgery, the larger proportion of younger patients compared to other countries remains valid. According to a study conducted in the United Kingdom [12], about 2.1\% of CRC patients are less than 40 years old. In contrast, in Korea, the proportion of CRC patients under 40 years of age is reported to be $6.5 \%$ [4]. As a result, changes to the recommended CRC screening age have been suggested. Currently, the screening program in Korea is an FOBT once every year after the age of 50 years. If a potential problem is detected on the FOBT, colonoscopy is recommended. However, these recommendations were made based on foreign 


\section{Coloproctology $\quad$ Tae-Hoon Lee, et al.
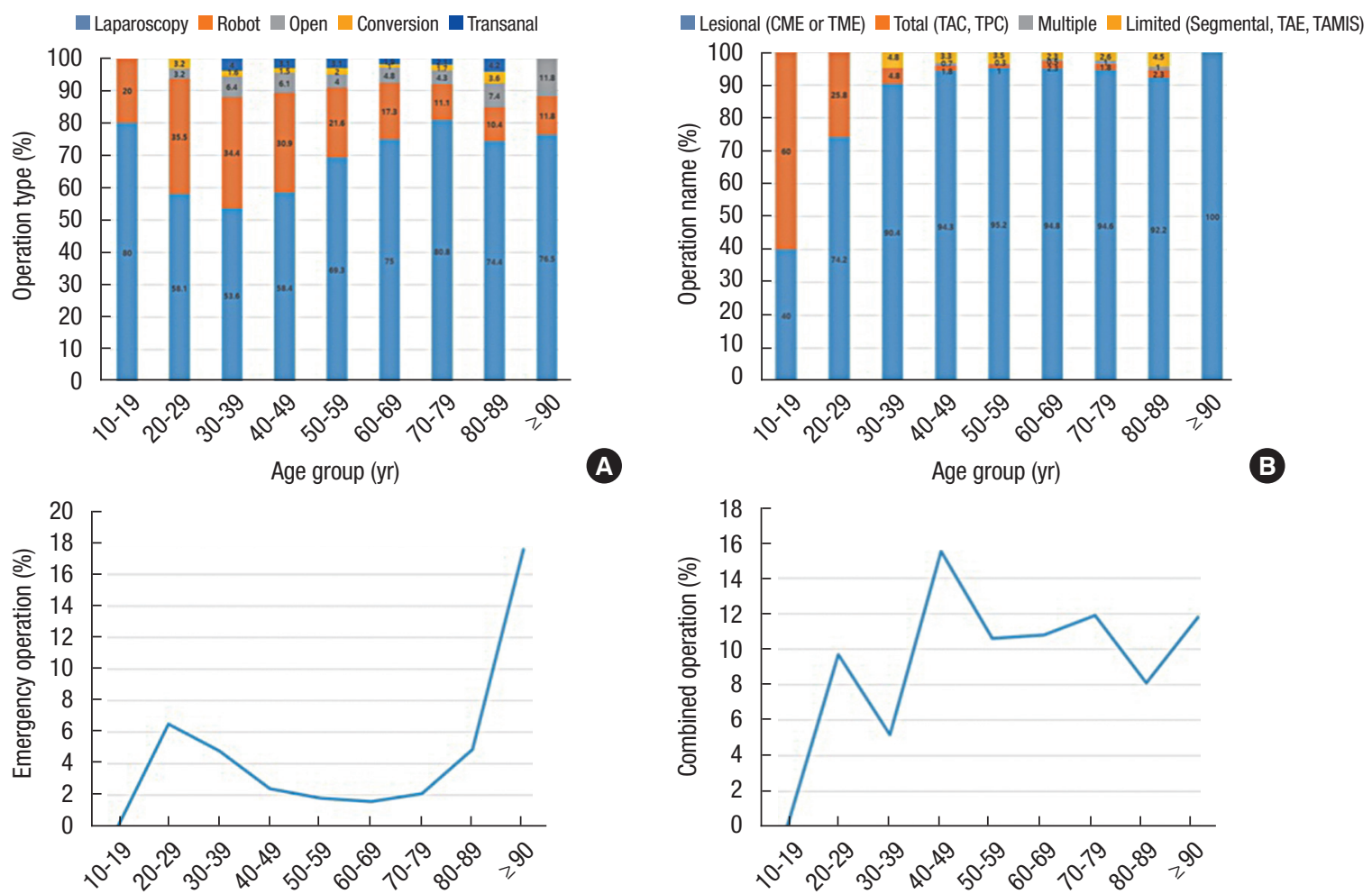

Age group (yr)

C
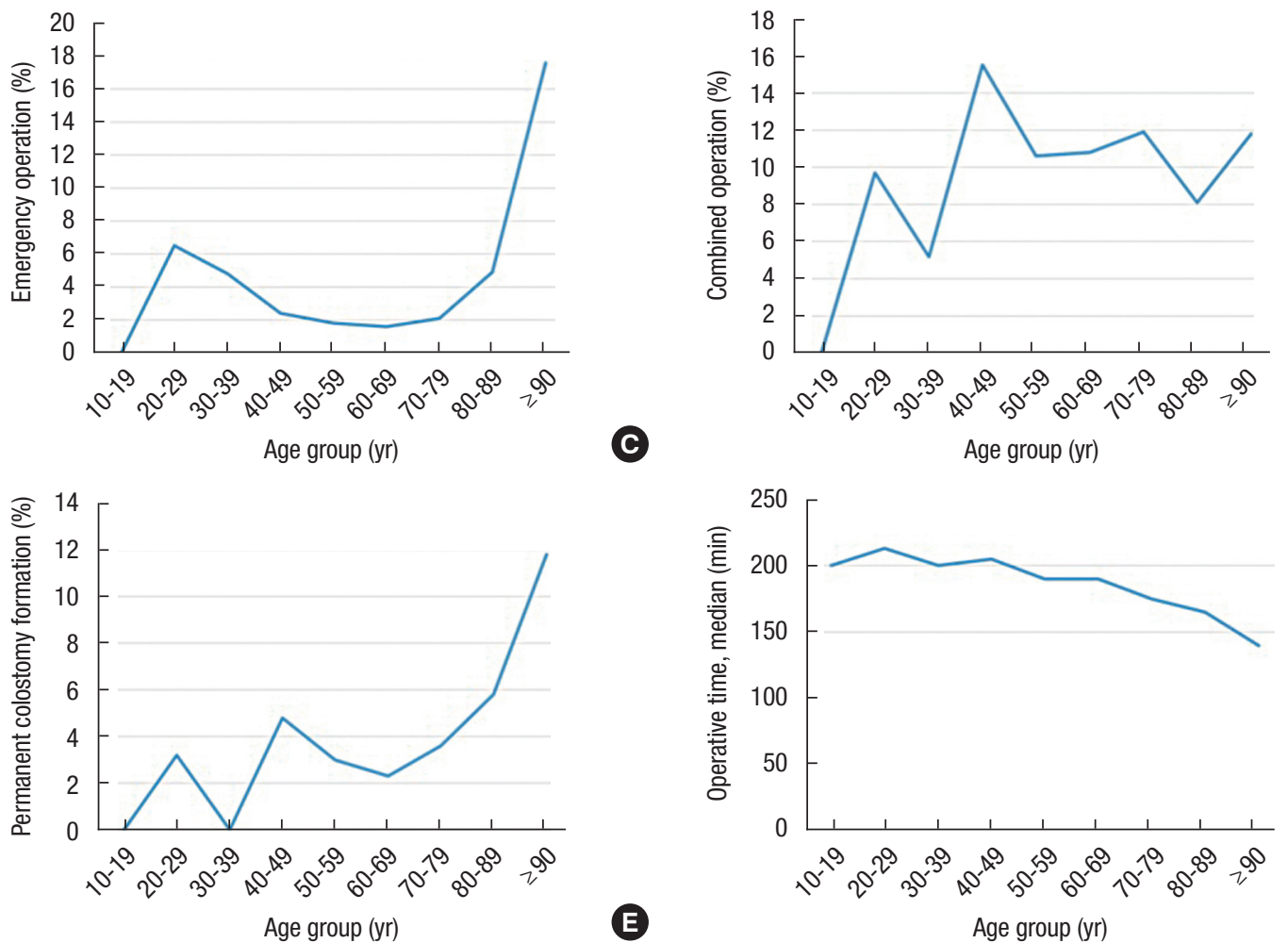

Age group (yr)

D)

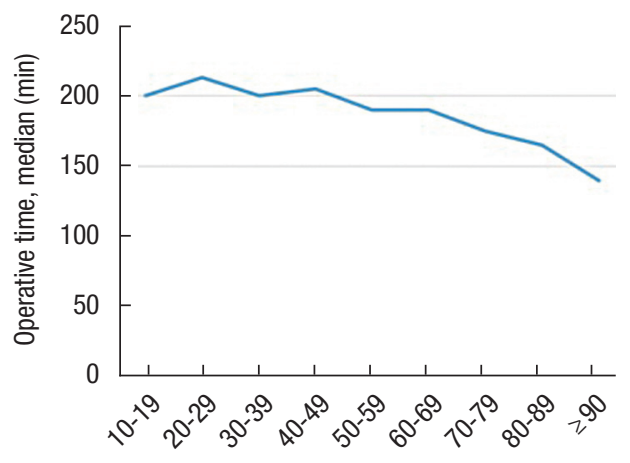

Age group (yr)

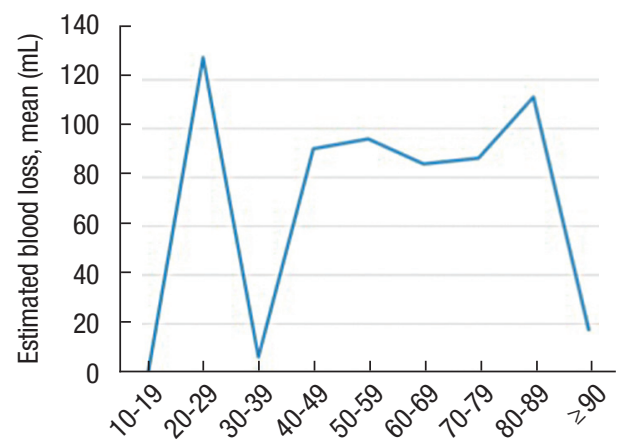

Age group (yr)

G

Fig. 1. Operative data by age for the study population. (A) Operation type. (B) Operation name. (C) Emergency operation. (D) Combined operation. (E) Permanent colostomy formation. (F) Operative time. (G) Estimated blood loss. CME, complete mesocolic excision; TME, total mesorectal excision; TAC, total abdominal colectomy; TPC, total proctocolectomy; TAE, transanal excision; TAMIS, transanal minimally invasive surgery. 
Table 3. Pathology data for the study population

\begin{tabular}{|c|c|c|c|c|c|c|c|c|c|}
\hline \multirow{2}{*}{ Variable } & \multicolumn{9}{|c|}{ Age group (yr) } \\
\hline & $10-19$ & $20-29$ & $30-39$ & $40-49$ & $50-59$ & $60-69$ & $70-79$ & $80-89$ & 90-99 \\
\hline \multicolumn{10}{|l|}{ pT stage (\%) } \\
\hline Tis & 60.0 & 29.0 & 6.4 & 5.7 & 8.0 & 7.9 & 6.3 & 6.1 & 0 \\
\hline T0 & 0 & 0 & 4.8 & 3.9 & 4.0 & 2.6 & 2.1 & 1.3 & 5.9 \\
\hline $\mathrm{T} 1$ & 20.0 & 6.5 & 8.8 & 6.6 & 10.8 & 10.5 & 8.9 & 4.9 & 0 \\
\hline T2 & 0 & 9.7 & 12.0 & 11.8 & 13.5 & 14.8 & 14.3 & 11.7 & 5.9 \\
\hline T3 & 0 & 41.9 & 52.8 & 61.7 & 54.2 & 54.5 & 58.1 & 63.1 & 64.7 \\
\hline T4 & 20.0 & 9.7 & 12.0 & 9.2 & 8.2 & 8.8 & 10.0 & 12.9 & 23.5 \\
\hline Unknown & 0 & 3.2 & 3.2 & 1.1 & 1.4 & 0.9 & 0.4 & 0 & 0 \\
\hline \multicolumn{10}{|l|}{ pN stage (\%) } \\
\hline NO & 40.0 & 58.1 & 55.2 & 50.1 & 56.5 & 57.8 & 58.7 & 57.3 & 41.2 \\
\hline N1 & 0 & 12.9 & 23.2 & 27.8 & 25.1 & 24.9 & 25.7 & 26.5 & 23.5 \\
\hline N2 & 20.0 & 22.6 & 16.0 & 17.5 & 13.9 & 13.4 & 12.4 & 11.7 & 35.3 \\
\hline Unknown & 40.0 & 6.5 & 5.6 & 4.6 & 4.5 & 3.8 & 3.2 & 4.5 & 0 \\
\hline \multicolumn{10}{|l|}{ No. of LN, mean } \\
\hline Positive LN & 2.7 & 2.5 & 1.9 & 1.8 & 1.8 & 1.8 & 1.5 & 1.3 & 2.6 \\
\hline Retrieved LN & 76.3 & 47.2 & 34.0 & 29.1 & 26.8 & 25.1 & 24.3 & 25.0 & 25.8 \\
\hline \multicolumn{10}{|l|}{ M stage (\%) } \\
\hline MO & 80.0 & 83.9 & 81.6 & 78.6 & 84.8 & 84.6 & 84.4 & 86.4 & 70.6 \\
\hline M1 & 20.0 & 16.1 & 17.6 & 20.8 & 14.9 & 15.2 & 15.5 & 13.3 & 29.4 \\
\hline Unknown & 0 & 0 & 0.8 & 0.7 & 0.3 & 0.2 & 0.1 & 0.3 & 0 \\
\hline \multicolumn{10}{|l|}{ Stage (\%) } \\
\hline 0 & 60.0 & 29.0 & 11.2 & 8.5 & 11.1 & 10.3 & 8.1 & 7.1 & 5.9 \\
\hline 1 & 20.0 & 9.7 & 15.2 & 12.9 & 18.4 & 19.1 & 18.2 & 12.6 & 5.9 \\
\hline 2 & 0 & 19.4 & 27.2 & 26.7 & 25.4 & 26.5 & 31.0 & 35.9 & 23.5 \\
\hline 3 & 0 & 19.4 & 25.6 & 28.9 & 27.9 & 27.0 & 26.0 & 29.1 & 35.3 \\
\hline 4 & 20.0 & 19.4 & 17.6 & 20.8 & 14.8 & 15.2 & 15.5 & 13.6 & 29.4 \\
\hline Unknown & 0 & 3.2 & 3.2 & 2.2 & 2.4 & 1.9 & 1.3 & 1.6 & 0 \\
\hline Tumor size (cm), mean & 4.3 & 4.3 & 4.7 & 4.6 & 4.3 & 4.3 & 4.6 & 5.3 & 8.2 \\
\hline \multicolumn{10}{|c|}{ Resection margin $(\mathrm{cm})$, mean } \\
\hline Proximal & 11.1 & 23.0 & 19.2 & 16.6 & 16.3 & 17.0 & 15.9 & 16.1 & 12.6 \\
\hline Distal & 42.0 & 5.9 & 6.6 & 6.0 & 6.8 & 8.0 & 9.1 & 10.6 & 10.4 \\
\hline Circumferential & NA & 0.5 & 0.6 & 0.7 & 0.7 & 0.8 & 0.8 & 0.8 & 0.3 \\
\hline
\end{tabular}

p, pathological; LN, lymph node; NA, not applicable.

statistics, and may not be appropriate for the Korean population. In both the national cancer statistics and our study, CRC patients aged 30 to 49 years account for about $10 \%$ to $13.5 \%$ of reported cases. We, therefore, propose that screening should start earlier than is currently recommended. Even in the West, the age at which CRC is diagnosed has decreased in recent years, and efforts are being made to lower the screening age to 45 years $[7,16,19]$. Also, it is necessary to pay attention to genetic counseling [23].
In our study, the proportion of rectal cancer was particularly high (mean, 46.4\%). This is thought to be because our hospital is specialized in robotic rectal cancer surgery. The distribution of cancer lesions also differed significantly between age groups, but the proportion of right-sided colon cancer was relatively high in the elderly patients [24-27]. It is consistent with other studies comparing different age groups. Yang et al. [24] reported that in patients over 70 years of age, the right-sided colon cancer rate was 


\section{Coloproctology}

Characteristics and outcomes of colorectal cancer surgery by age in a tertiary center in Korea:

a retrospective review

Tae-Hoon Lee, et al.

Table 4. Postoperative data for the study population

\begin{tabular}{|c|c|c|c|c|c|c|c|c|c|}
\hline \multirow{2}{*}{ Variable } & \multicolumn{9}{|c|}{ Age group (yr) } \\
\hline & $10-19$ & $20-29$ & $30-39$ & $40-49$ & $50-59$ & $60-69$ & $70-79$ & $80-89$ & $90-99$ \\
\hline Gas (day), median & 1 & 2 & 2 & 2 & 2 & 2 & 2 & 2 & 3 \\
\hline Stool (day), median & 2 & 2 & 2 & 2 & 3 & 3 & 3 & 3 & 4 \\
\hline Feed (day), median & 2 & 2 & 2 & 2 & 2 & 2 & 2 & 2 & 4.5 \\
\hline Postoperative hospital stay (day), median & 6 & 8 & 8 & 8 & 8 & 8 & 8 & 8 & 10 \\
\hline Postoperative complication (\%) & 20.0 & 29.0 & 26.4 & 25.6 & 22.9 & 24.8 & 29.2 & 35.0 & 52.9 \\
\hline Leakage & 0 & 3.2 & 4.8 & 5.9 & 6.5 & 5.7 & 4.7 & 3.9 & 5.9 \\
\hline Intraabdominal abscess & 0 & 0 & 3.2 & 2.4 & 1.6 & 1.1 & 1.7 & 0 & 5.9 \\
\hline Wound infection & 0 & 3.2 & 2.4 & 1.3 & 1.2 & 1.2 & 2.4 & 2.6 & 5.9 \\
\hline lleus & 0 & 3.2 & 11.2 & 10.3 & 8.3 & 9.2 & 10.7 & 8.4 & 35.3 \\
\hline Bleeding & 0 & 3.2 & 2.4 & 0.7 & 0.9 & 0.9 & 1.0 & 1.9 & 5.9 \\
\hline Stoma-related & 0 & 0 & 0 & 0.4 & 0.2 & 0.3 & 0.5 & 0 & 5.9 \\
\hline Pulmonary & 0 & 3.2 & 0.8 & 1.1 & 0.8 & 1.6 & 1.8 & 3.9 & 5.9 \\
\hline Cardiovascular & 0 & 3.2 & 0 & 0 & 0.2 & 0.4 & 0.4 & 1.3 & 5.9 \\
\hline Nephrology & 0 & 3.2 & 0 & 0.4 & 0.2 & 0.9 & 0.9 & 1.3 & 5.9 \\
\hline Voiding & 20.0 & 0 & 0.8 & 0.4 & 0.8 & 1.4 & 1.4 & 1.3 & 5.9 \\
\hline Chyle & 20.0 & 9.7 & 3.2 & 3.7 & 4.1 & 4.4 & 5.5 & 4.5 & 5.9 \\
\hline Others & 0 & 3.2 & 3.2 & 2.4 & 2.4 & 3.5 & 4.8 & 9.4 & 11.8 \\
\hline Reoperation (\%) & 0 & 0 & 1.6 & 2.4 & 3.6 & 3.6 & 3.1 & 3.2 & 5.9 \\
\hline Postoperative mortality (\%) & 0 & 3.2 & 0 & 0.4 & 0.3 & 1.1 & 0.9 & 2.3 & 5.9 \\
\hline Adjuvant treatment (\%) & 20.0 & 48.4 & 59.2 & 65.4 & 57.5 & 55.9 & 42.8 & 21.7 & 11.8 \\
\hline Chemotherapy & 20.0 & 48.4 & 56.8 & 63 & 55.6 & 54.5 & 41.0 & 20.4 & 11.8 \\
\hline Radiotherapy & 0 & 0 & 2.4 & 2.4 & 1.9 & 1.4 & 1.8 & 1.3 & 0 \\
\hline Recurrence (\%) & 20.0 & 16.1 & 15.2 & 19.9 & 16.3 & 16.4 & 13.9 & 12.6 & 11.8 \\
\hline Local & 0 & 3.2 & 0.8 & 2.2 & 2.5 & 1.6 & 1.6 & 1.9 & 5.9 \\
\hline Systemic & 20.0 & 9.7 & 6.4 & 7.0 & 6.8 & 7.2 & 5.7 & 7.1 & 5.9 \\
\hline Progression & 0 & 6.5 & 8.0 & 11.4 & 7.7 & 7.9 & 7.1 & 3.6 & 5.9 \\
\hline Death (\%) & 20.0 & 9.7 & 11.2 & 12.3 & 8.6 & 14.1 & 15.8 & 20.1 & 23.5 \\
\hline Follow-up (mo), mean & 43.2 & 29.0 & 35.9 & 35.2 & 34.8 & 34.1 & 28.0 & 19.0 & 14.1 \\
\hline
\end{tabular}
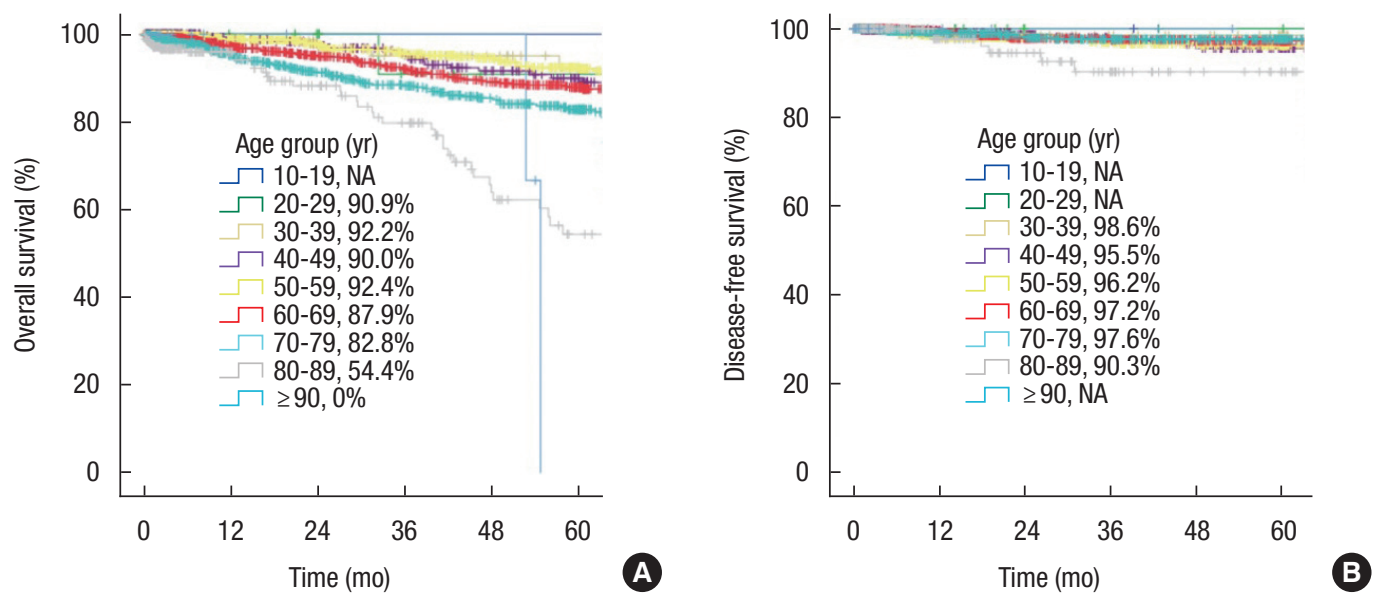

Fig. 2. Comparison of 5-year survival rate by age group (stage 1-3). (A) Overall survival and (B) disease-free survival. NA, not applicable. 
2 to 3 times higher than that of young patients (right/left colon cancer ratio: 1.00 in patients $<40$ years vs. 2.40 in patients $>70$ years). On the other hand, young patients often had multiple lesions likely because most of them were hereditary CRCs, such as familial adenomatous polyposis or hereditary nonpolyposis CRC $[28,29]$. For this reason, the proportion of young patients who underwent total abdominal colectomy or total proctocolectomy was high in our study.

At our institution, most of the elderly patients underwent minimally invasive surgery, and radical resection with curative intent was performed rather than limited surgery. Despite the relatively high rate of emergency surgery, the rate of open surgery was limited to around $10 \%$ among patients aged 80 to 99 years. The preferential use of minimally invasive surgery is expected to result in less pain, and more rapid postoperative recovery. In our previous study, we reported that it was possible to apply fast-track treatment after laparoscopic surgery in old patients [30]. In this study, although mortality and postoperative complications such as ileus occurred frequently among the elderly patients, these outcomes appear to have been the result of emergency surgery. Even in the scope of surgery, active oncologic treatment was performed for all ages. As a result, the 5-year DFS was over 90\% even among patients aged 80 to 89 years. In elderly patients, it is often difficult to implement adjuvant chemotherapy, so we postulate that providing active surgical treatment will help improve the quality of life for the remainder of the patient's life.

There are several limitations to our study. First, due to the nature of the disease, there were very few patients in their teens, 20s, and 90 s, and the follow-up duration for these patients was short. In addition, analysis of cancer-specific survival was not performed. Second, data from patients who did not undergo surgery for various reasons or who received palliative surgery were not included in this study; this study design may have led to bias with regard to the age-specific composition of the disease, as only patients in good condition were selected for surgery, and survival may have been evaluated as overly good, especially among the elderly. Third, our institution may not be representative of most institutions that perform CRC surgeries. Given our hospital is one of the few institutions that specialize in minimally invasive surgery in Korea, our surgical population and surgical approaches may differ from those at other institutions.

Despite these shortcomings, this study, based on data from more than 4,000 patients, provides valuable information on the agespecific characteristics of CRC in the East, and particularly in Korea. Recently, many studies using data from the Health Insurance Corporation in Korea have been reported, and our study has the advantage that it contains clinical information that such studies cannot provide. In addition, our findings are particularly relevant in light of the aging of the Korean population, given surgery is being performed very actively even in the elderly, especially using minimally invasive techniques that provide good surgical and oncological outcomes.
In our study, we found young CRC patients were relatively common in Korea compared to Western countries, and many surgeries that used minimally invasive techniques were performed in elderly patients. When considering the age distribution of CRC patients in Korea, it is necessary to consider a protocol that starts screening from an earlier age than is currently recommended. In addition, in consideration of the ongoing aging of the Korean population, surgical and oncological outcomes may be improved by actively treating elderly CRC patients based upon their general condition rather than their chronological age.

\section{CONFLICT OF INTEREST}

No potential conflict of interest relevant to this article was reported.

\section{FUNDING}

None.

\section{REFERENCES}

1. Bray F, Ferlay J, Soerjomataram I, Siegel RL, Torre LA, Jemal A. Global cancer statistics 2018: GLOBOCAN estimates of incidence and mortality worldwide for 36 cancers in 185 countries. CA Cancer J Clin 2018;68:394-424.

2. Jung KW, Won YJ, Kong HJ, Lee ES. Prediction of cancer incidence and mortality in Korea, 2018. Cancer Res Treat 2018;50: 317-23.

3. Hur H, Oh CM, Won YJ, Oh JH, Kim NK. Characteristics and survival of Korean patients with colorectal cancer based on data from the Korea Central Cancer Registry data. Ann Coloproctol 2018;34:212-21.

4. Nam S, Choi YJ, Kim DW, Park EC, Kang JG. Risk factors for colorectal cancer in korea: a population-based retrospective cohort study. Ann Coloproctol 2019;35:347-56.

5. Siegel RL, Fedewa SA, Anderson WF, Miller KD, Ma J, Rosenberg PS, et al. Colorectal cancer incidence patterns in the United States, 1974-2013. J Natl Cancer Inst 2017;109:djw322.

6. Chung RY, Tsoi KK, Kyaw MH, Lui AR, Lai FT, Sung JJ. A population-based age-period-cohort study of colorectal cancer incidence comparing Asia against the West. Cancer Epidemiol 2019;59:2936.

7. Gabriel E, Attwood K, Al-Sukhni E, Erwin D, Boland P, Nurkin S. Age-related rates of colorectal cancer and the factors associated with overall survival. J Gastrointest Oncol 2018;9:96-110.

8. Cheong C, Oh SY, Kim YB, Suh KW. Differences in biological behaviors between young and elderly patients with colorectal cancer. PLoS One 2019;14:e0218604.

9. Kaplan MA, Ozaydin S, Yerlikaya H, Karaagac M, Gumus M, Cil T, et al. Clinicopathologic and prognostic differences between three different age groups (child/adolescent, young adults, and adults) 
of colorectal cancer patients: a multicentre study. Oncol Res Treat 2019;42:516-22.

10. Campos FG. Colorectal cancer in young adults: a difficult challenge. World J Gastroenterol 2017;23:5041-4.

11. Saraste D, Järås J, Martling A. Population-based analysis of outcomes with early-age colorectal cancer. Br J Surg 2020;107:301-9.

12. Anele CC, Askari A, Navaratne L, Patel K, Jenkin JT, Faiz OD, et al. The association of age with the clinicopathological characteristics and prognosis of colorectal cancer: a UK single-centre retrospective study. Colorectal Dis 2020;22:289-97.

13. Sung JJY, Chiu HM, Jung KW, Jun JK, Sekiguchi M, Matsuda T, et al. Increasing trend in young-onset colorectal cancer in Asia: more cancers in men and more rectal cancers. Am J Gastroenterol 2019; 114:322-9.

14. Gabriel E, Ostapoff K, Attwood K, Al-Sukhni E, Boland P, Nurkin S. Disparities in the age-related rates of colorectal cancer in the United States. Am Surg 2017;83:640-7.

15. Siegel RL, Torre LA, Soerjomataram I, Hayes RB, Bray F, Weber TK, et al. Global patterns and trends in colorectal cancer incidence in young adults. Gut 2019;68:2179-85.

16. Fedewa SA, Siegel RL, Goding Sauer A, Bandi P, Jemal A. Colorectal cancer screening patterns after the American Cancer Society's recommendation to initiate screening at age 45 years. Cancer 2020;126:1351-3.

17. Jeon J, Du M, Schoen RE, Hoffmeister M, Newcomb PA, Berndt SI, et al. Determining risk of colorectal cancer and starting age of screening based on lifestyle, environmental, and genetic factors. Gastroenterology 2018;154:2152-64.

18. Virostko J, Capasso A, Yankeelov TE, Goodgame B. Recent trends in the age at diagnosis of colorectal cancer in the US National Cancer Data Base, 2004-2015. Cancer 2019;125:3828-35.

19. Abualkhair WH, Zhou M, Ahnen D, Yu Q, Wu XC, Karlitz JJ. Trends in incidence of early-onset colorectal cancer in the United States among those approaching screening age. JAMA Netw Open 2020;3:e1920407.

20. Zawadzki M, Krzystek-Korpacka M, Rząca M, Czarnecki R,
Obuszko Z, Witkiewicz W. Colorectal surgery in elderly population. Pol Przegl Chir 2018;90:29-34.

21. Al-Refaie WB, Parsons HM, Habermann EB, Kwaan M, Spencer MP, Henderson WG, et al. Operative outcomes beyond 30-day mortality: colorectal cancer surgery in oldest old. Ann Surg 2011; 253:947-52.

22. Sakamoto Y, Miyamoto Y, Tokunaga R, Akiyama T, Daitoku N, Hiyoshi $Y$, et al. Long-term outcomes of colorectal cancer surgery for elderly patients: a propensity score-matched analysis. Surg Today 2020;50:597-603.

23. Wells K, Wise PE. Hereditary colorectal cancer syndromes. Surg Clin North Am 2017;97:605-25.

24. Yang L, Xiong Z, He W, Xie K, Liu S, Kong P, et al. Proximal shift of colorectal cancer with increasing age in different ethnicities. Cancer Manag Res 2018;10:2663-73.

25. Cheng X, Chen VW, Steele B, Ruiz B, Fulton J, Liu L, et al. Subsitespecific incidence rate and stage of disease in colorectal cancer by race, gender, and age group in the United States, 1992-1997. Cancer 2001;92:2547-54.

26. Lu P, Fields AC, Vise AS, Shabat G, Irani JL, Bleday R, et al. Anatomic distribution of colorectal adenocarcinoma in young patients. Dis Colon Rectum 2019;62:920-4.

27. Reif de Paula T, Simon HL, Profeta da Luz MM, Keller DS. Right sided colorectal cancer increases with age and screening should be tailored to reflect this: a national cancer database study. Tech Coloproctol 2021;25:81-9.

28. Mauri G, Sartore-Bianchi A, Russo AG, Marsoni S, Bardelli A, Siena S. Early-onset colorectal cancer in young individuals. Mol Oncol 2019;13:109-31.

29. You YN, Lee LD, Deschner BW, Shibata D. Colorectal cancer in the adolescent and young adult population. JCO Oncol Pract 2020; 16:19-27.

30. Baek SJ, Kim SH, Kim SY, Shin JW, Kwak JM, Kim J. The safety of a "fast-track" program after laparoscopic colorectal surgery is comparable in older patients as in younger patients. Surg Endosc 2013;27:1225-32.

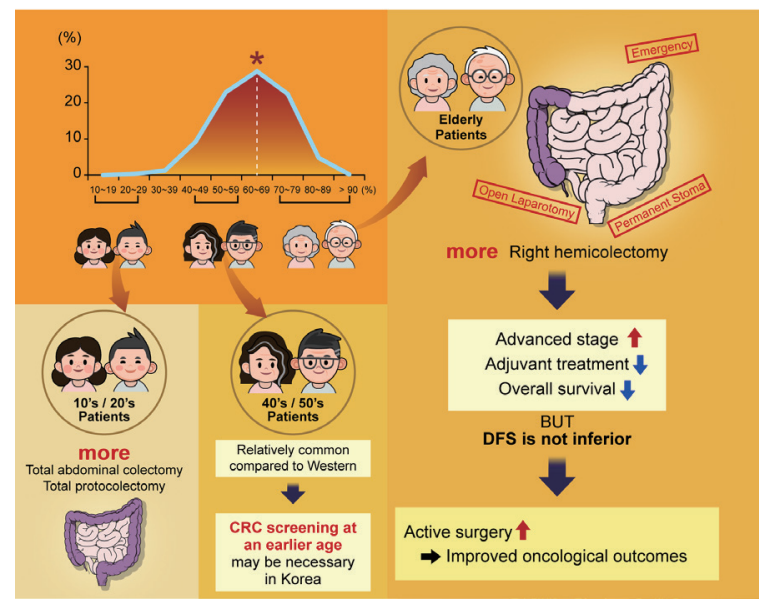

